\title{
Towards Nanomaterials for Cancer Theranostics: A System of DNA-Modified Magnetic Nanoparticles for Detection and Suppression of RNA Marker in Cancer Cells
}

\author{
Saira Bakshi ${ }^{1}$, Andrey Zakharchenko ${ }^{2}$, Sergiy Minko ${ }^{2, *(\mathbb{D}, \text { Dmitry M. Kolpashchikov }}{ }^{3, *(1)}$ \\ and Evgeny Katz ${ }^{1, *}$ \\ 1 Department of Chemistry and Biomolecular Science, Clarkson University, Potsdam, NY 13699-5810, USA; \\ bakshisf@clarkson.edu \\ 2 Nanostructured Materials Lab, University of Georgia, Athens, GA 30602, USA; zah9000@gmail.com \\ 3 Chemistry Department, University of Central Florida, 4000 Central Florida Boulevard, Orlando, \\ FL 32816-2366, USA \\ * Correspondence: sminko@uga.edu (S.M.); Dmitry.Kolpashchikov@ucf.edu (D.M.K.); \\ ekatz@clarkson.edu (E.K.)
}

Received: 24 January 2019; Accepted: 1 April 2019; Published: 4 April 2019

\begin{abstract}
Theranostics of cancer using smart biocompatible materials can enable early cancer diagnostics and treatment. Here, we report on a DNA-nanoparticle functional material, which can simultaneously report the presence of an mRNA cancer biomarker and trigger its degradation in cultured cells. The nanodevice consists of two species of magnetic beads, each of which is conjugated with different components of a multicomponent deoxyribozyme (DZ) sensor. The system is activated only under two conditions: (i) in the presence of a specific target mRNA and (ii) when a magnetic field is applied. We demonstrate that delivery of such a system is markedly enhanced by the application of a magnetic field. The system not only fluorescently detects target mRNA in cultured MCF-7 cancer cells, but also induces its downregulation. Thus, the two-component magnetic nanoparticle system has characteristics of a material that can be used for cancer theranostics.
\end{abstract}

Keywords: RNA analysis; magnetic nanoparticles; theranostics; cancer biomarker; deoxyribozyme; biosensor

Cancer theranostics is among the major focuses of nanotechnology and nanomaterials [1,2]. Theranostics combines diagnosis and therapeutics and aims to eliminate multi-step procedures and reduce delays in treatment. Application of magnetic nanoparticles in cancer theranostics has been driven in large part due to the success of magnetic nanoparticles as contrast agents in magnetic resonance imaging [1], as well as the development of magnetic hyperthermia [3,4]. These individual features, when combined into one functional material, allow simultaneous therapeutic action and monitoring of the therapeutic action. These effects are mostly based on physical properties of the magnetic nanoparticles rather than their chemical composition. In this study we explore another approach for the design of cancer theranostic material based on magnetic nanoparticles conjugated with a deoxyribozyme (DZ) probe complementary to a known mRNA biomarker for metastatic breast adenocarcinoma. Deoxyribozymes [5-7] are catalytic DNA molecules that are widely used in the areas of biocomputational logic gates and circuits (DNA computing) [8,9], programmable materials [10], ultrasensitive analytical methods [11,12], and for therapeutic applications [13-15].

Recently, we reported on a magnetic field-activated binary deoxyribozyme (MaBiDZ) fluorescent sensor for mRNA detection in intact live cells [16,17] based on binary deoxyribozyme (BiDZ) 
technology [18-20], as shown in Figure 1. In this approach, two DNA strands-DZa and $\mathrm{DZb}$ - specifically recognize a nucleic acid analyte and form a DZ catalytic core, which cleaves a fluorophore and quencher labeled substrate, F-sub, thus producing a fluorescent signal, as shown in Figure 1. Notably, the signal appears only in the presence of the DNA/RNA analyte species which are needed for assembling the catalytic BiDZ core. A BiDZ sensor was applied for molecular diagnostics of diseases [21-23]. The MaBiDZ system, which includes DNA-functionalized magnetic nanoparticles, was developed for the detection of a specific biomarker inside cancer cells. The system consists of two species of $100 \mathrm{~nm}$ magnetic beads (MaB)-MaB1 and MaB2-as shown in Figure 2. The DZa strand was covalently conjugated to MaB1, while F-sub was non-covalently attached to MaB2 via hybridization to the covalently bound hook strand, as shown in Figure 2. A DNA or RNA analyte hybridized to DZa and DZb strands enables formation of the DZ catalytic core. However, the system does not produce the fluorescent signal unless a magnetic field is applied because the catalytic core is spatially separated from F-sub $[16,17]$. Application of an external magnetic field induces aggregation of the MaB1 and MaB2, thus bringing the activated BiDZ sensor in close proximity to F-sub followed by F-sub cleavage, thus resulting in a fluorescence signal. MaBiDZ is the first magnetic system that enables magnetic field-mediated control of sensors' activity inside cells. It was able to specifically detect Twist mRNA (a cancer biomarker) in MCF-7 cell culture [16]. Moreover, we demonstrated that the magnetic field facilitates internalization of the MaBiDZ system in cell cultures and that sensing of mRNA can occur within $2.5 \mathrm{~h}$, shortly after endosomal escape (compared with at least $8 \mathrm{~h}$ required for the analysis with NanoFlares technology [24]).

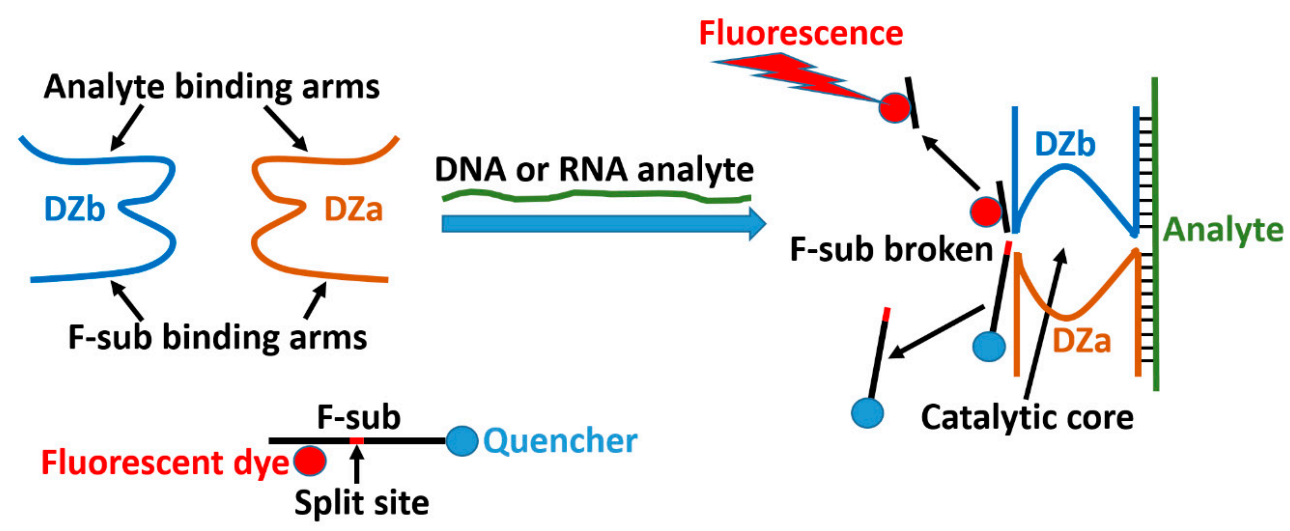

Figure 1. Binary deoxyribozyme sensor (BiDZ) as reported earlier [15]. DNA strands DZa and DZb hybridize to an adjacent position of the analyte and form a deoxyribozyme catalytic core, which cleaves fluorogenic F-sub and increases sample fluorescence. Note that the BiDZ operates in a solution and it is not responsive to the magnetic field. The present scheme illustrates the general concept of the BiDZ sensor operation and it does not correspond to the magneto-activated system used in the present study.

Table 1. DNA sequences used in this study.

\begin{tabular}{cr}
\hline Name $^{\text {a }}$ & Sequence \\
\hline DZa & $\begin{array}{r}5^{\prime} \text {-NH2/AAA AAA AAA AAA AAA AAA AAC GAG CGG } \\
\text { CTC AGC TAC GCC T AC AAC CGA GAG AGG AAA C }\end{array}$ \\
\hline DZb & 5'-CCA GGG A GG CTA GCT TCT CGG TCT GGA GGA TGG AG \\
\hline F-Sub & $5^{\prime}$-CGGT ACA TTG TAG AAG TT AAG GTTFAM TCC TCg uCC CTG GGC A-BHQ1 \\
\hline Hook & 5'-NH2/AAA AAA AAA AAA AAA AAA AA/iSp9/AAC \\
TTC TAC AAT GTA CCG \\
\hline Forward Twist Primer & 5'-GGAGTCCGCAGTCTTACGAG \\
\hline Reverse Twist Primer & 5'-TCTGGAGGACCTGGTAGAGG \\
\hline $\begin{array}{c}\text { a iSp9-triethylene glycol linker; FAM attached to the DNA is a fluorescein derivative; BHQ1-“Black Hole } \\
\text { Quencher” is a fluorescence quencher; ribonucleotides are in lower case. }\end{array}$
\end{tabular}




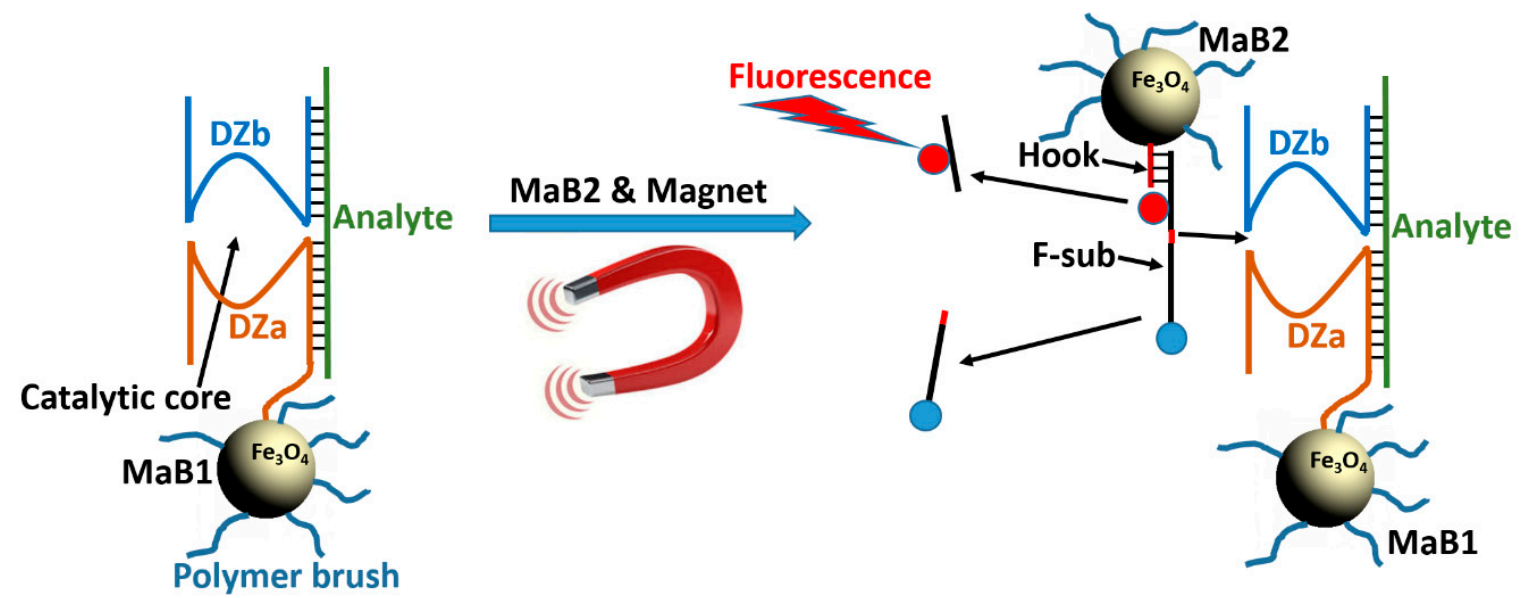

Figure 2. MaBiDZ used in this study. Magnetic bead (MaB1)-bound DZa forms a catalytic core with $\mathrm{DZb}$ in the presence of an analyte. The activated nanoreactor produces signal only when: (i) a second species of magnetic beads, MaB2 carrying F-sub is present, and (ii) a magnetic field that aggregates MaB1 and MaB2 is applied. See the DNA sequences in Table 1.

Antisense oligonucleotides [25] regulate gene expression by binding target mRNA and preventing translation and through interactions with ribonuclease $\mathrm{H}$ (RNase H). Given that after cell entry, mRNA binding is the first step in MaBiDz sensing, MaBiDz could function as a therapeutic agent by the antisense mechanism. While there has been significant investment in a number of oligonucleotide-based approaches for cancer therapy, including antisense oligonucleotides [26], RNAi and CRISPR/Cas9 [27], there is no clinically significant oligonucleotide-based anticancer treatment as of today. In this work, we investigated the potential of the MaBiDz system to be used as an anticancer gene therapy agent.

One major barrier of gene therapy approaches is the delivery and monitoring the delivery of gene therapy agents to cancer cells [28]. Indeed, nucleic acid delivery to cells in culture is to a large extent a diffusion-limited process if the nucleic acid shuttle (the vector) is of nanometric size; transport to the target cells is a limiting factor in nucleic acid delivery [24,29]. Hence, apart from the major biological barriers (e.g., blood plasma), delivery of only a fraction of the applied oligonucleotide agent via cellular membranes to the cytoplasm of target cells represents a major limitation to the bioavailability of anticancer oligonucleotide agents [29]. Indeed, the few reported tools in the literature require several hours of incubation [24,29], which has the inherent side effects of cellular toxicity and lysosomal sequestration. This is in contrast to functionalized magnetic nanoparticles, in which case active ingredients associated with magnetic particles are concentrated at a target site by magnetic force [30]. Indeed, we previously showed that MaBiDz-generated fluorescence upon detection of Twist mRNA in MCF-7 cells at $2.5 \mathrm{~h}$ was at least 2-fold greater with an applied magnetic field than without. In in vitro studies, MaBiDz also demonstrated a nearly 2-fold greater mRNA detection within $20 \mathrm{~min}$ with an applied magnetic field than without [16].

Previous findings $[30,31]$ suggest this magnetic-field-induced enhancement in the rate of $\mathrm{MaBiDz}$ transport occurs due to the following two reasons: (i) the magnetic field accelerates transport of $\mathrm{MaBiDz}$ to the target cell following an aggregation of MaBiDz on the cell surfaces; (ii) it also enhances uptake through membranes via magnetic force, allowing cellular internalization to proceed at a greater rate. Thus, although the applied dose may be the same in magnet ON/OFF controls, the effective uptake inside the cells is vastly different. Normally, larger doses are required to achieve an enhanced therapeutic or sensing effect. Additionally, the magnetic field causes MaBiDz to aggregate in close proximity to cells, decreasing the time required to diffuse to or sediment on the cell surface. Achieving the same frequency of MaBiDz-target cell contact may take hours without a magnetic field [24,29]. 
Thus, the use of a magnetic field can impart efficacy enhancement in both time and dosage, increasing efficiency and reducing toxicity.

To quantify and validate this previously observed enhancement, we first measured the magnetic nanoparticle responsiveness, as shown in Figure 3. We placed a magnet under a cuvette containing a suspension of superparamagnetic $\mathrm{MaB}$ and measured the suspension clarification kinetics using UV absorbance at $317 \mathrm{~nm}$. We used this to derive a magnetophoretic velocity of ca. $0.5 \mu \mathrm{m} \mathrm{s}^{-1}$. We then compared this with the sedimentation velocity of the nanoparticles without a magnetic field and determined this to be $6.9 \times 10^{-3} \mu \mathrm{m} \mathrm{s}^{-1}$ (see Supplementary Materials (SM), Tables S2-S4, for calculations) - a difference of ca. 100-fold. This supported our earlier observations of enhanced magnetic-field-induced transport of MaBiDz.

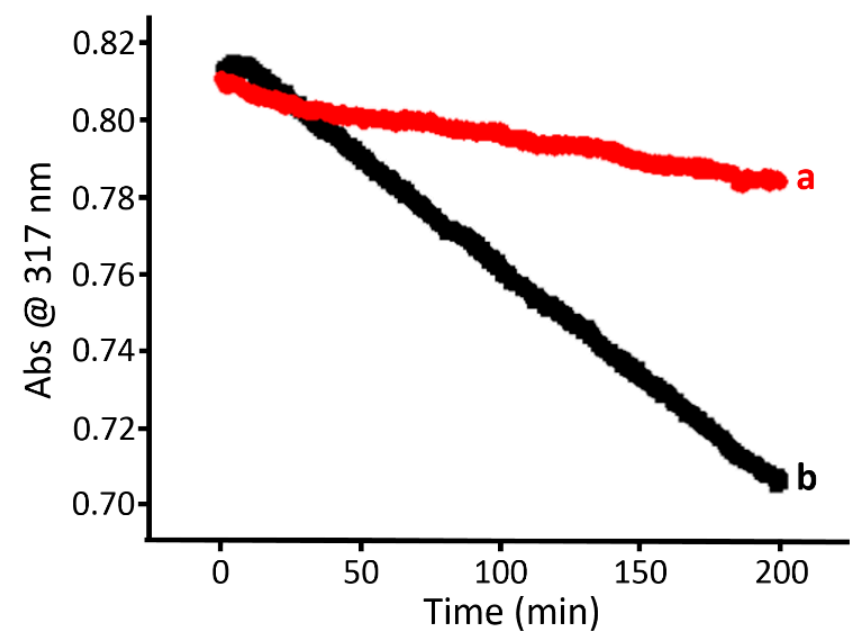

Figure 3. In vitro characterization of magnetic beads (MaB) mobility: (a) optical changes due to sedimentation of the $\mathrm{MaB}$ in the absence of a magnetic field, (b) optical changes due to magnetophoretic mobility of the MaB in the presence of a magnetic field (ca. $0.3 \mathrm{~T}$ ).

To investigate if the enhanced transport translates to the enhanced uptake of the MaB, we quantified cellular uptake of Quasar 670-tagged, oligo-modified $\mathrm{MaB}$ at various time points, with and without an applied magnetic field. We first imaged internalized, fluorescently-tagged MaB at the respective points, with and without magnetic field, using confocal microscopy. For the "Magnet ON" control we placed a magnet below the cell culture dish. Using this series of images, we used Image J software to determine the fluorescence per cell, as shown in Figure 4. Results demonstrate that the cells with the internalized MaB in the magnet ON/OFF populations were most distinct at $2 \mathrm{~h}$, as shown in Figure 4B.

After quantifying the advantage of the magnetic field with regard to cellular uptake, and determining the optimal temporal window for uptake, we investigated the ability of MaBiDZ to reduce the concentration of targeted Twist mRNA in MCF-7 cell culture. We chose to target Twist mRNA as it has been shown to be a biomarker for metastatic breast adenocarcinoma [32]. MCF-7 were incubated with Twist-specific MaBiDz $(0.50,1.00$, or $2.00 \mathrm{pM})$ for 2, 4, 6, and $8 \mathrm{~h}$. Following treatment, the cells were harvested, and the relative abundance of Twist mRNA was measured using qPCR. Twist levels were normalized to ribosomal mRNA, an off-target gene. In a control experiment, we measured Twist mRNA level in untreated MCF-7 cells or treated with DNA-free magnetic particles ("particles only" controls) (see Tables S8-S11 in Supplementary Materials). 

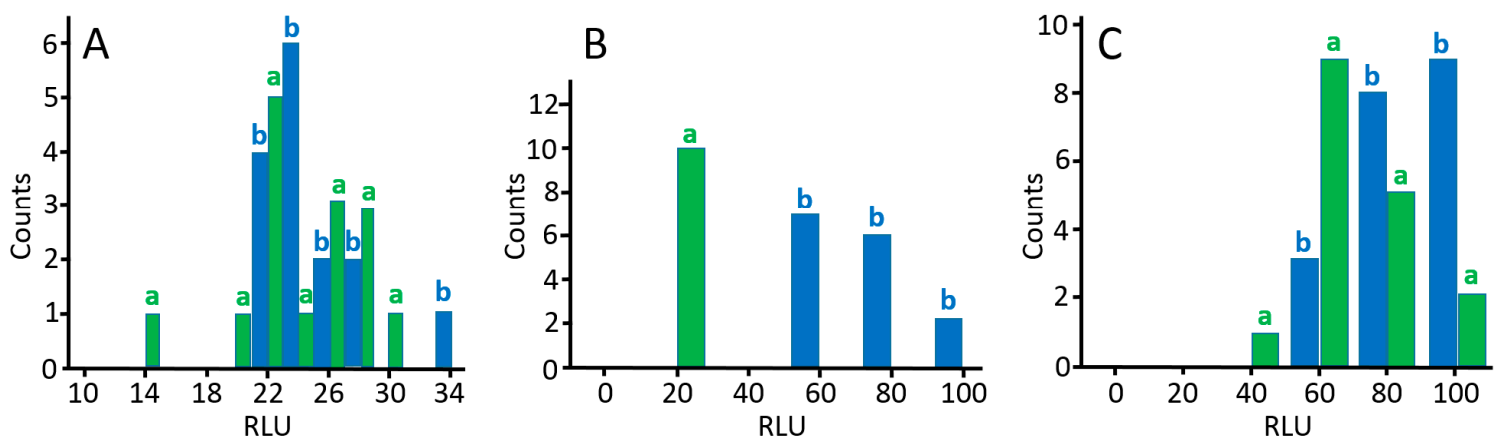

Figure 4. Graphs of pivot tables showing distribution of relative light units (RLU) in MCF-7 cells at (A) $1 \mathrm{~h}$, (B) $2 \mathrm{~h}$, and (C) $3 \mathrm{~h}$ for cells incubated with Quasar-670-modified MaB, with (blue bars-b) and without (green bars-a) an applied magnetic field. Fluorescence intensities per cell were measured using Image J software using a collection of confocal microscopy images taken at the respective time points.

In all samples, the level of Twist mRNA was lower in the presence of a magnetic field, as shown in Figure 5A(a-d) (red bars), compared to its absence (blue bars). The effect of the magnetic field on \% knockdown of Twist mRNA is summarized in Figure 5B. Based on the obtained results, we conclude the following: (i) there is a dose-dependent downregulation of Twist mRNA both in the presence and in the absence of magnetic field, (ii) for each concentration, the effect of the magnetic field decreases over time, although more drastically for the lower concentration, and (iii) the magnetic field is not required for therapeutic efficacy at longer time points when the concentration of MaBiDz is $2 \mathrm{pM}$.
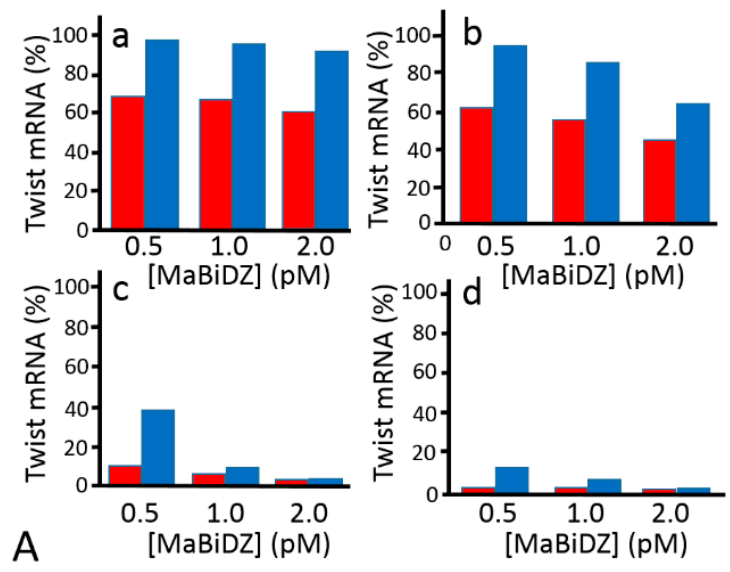



Figure 5. Levels of Twist mRNA as determined by qPCR experiments. (A) Dose-dependent knockout for (a) 2, (b) 4, (c) 6, and (d) $8 \mathrm{~h}$ with (red) and without (blue) an applied magnetic field. (B) The effect of the magnetic field on \% knockdown of Twist mRNA was examined over time. MaBiDz were incubated in MCF-7 cell culture for various time intervals $(2,4,6$, and $8 \mathrm{~h}$ ), with and without a magnetic field applied. The \% knockdown was determined by qPCR at each time point for both controls. The ratios (unitless) of mRNA knockdown with and without a magnetic field are shown at the highest concentration used $(2.00 \mathrm{pM}$, blue) and lowest concentration used ( $0.5 \mathrm{pM}$, red), while the $\%$ knockdown of the "Magnet $\mathrm{ON}^{\prime}$ control at $2.00 \mathrm{pM} \mathrm{MaB}$ is shown in green. Results show that as the extent of Twist knockdown progresses, the effect of the magnet is less pronounced. This diminishing enhancement in knockdown due to the magnetic field application is more pronounced at higher concentrations of MaB. Each bar in panel A represents the average of a set of three measurements. Calculations for standard deviation are shown in Table S10 in the Supplementary Materials. 
In summary, we have designed, synthesized, and characterized a nanoconjugate that can both detect and regulate intracellular mRNA levels. These nanoconjugates signal the presence of target mRNA with the cleavage of a fluorophore-quencher pair, which results in an increase in fluorescence. The target binding and response of the MaBiDz is highly efficient and depletes mRNA levels by as much as $99 \%$ in a dose-dependent manner. Although similar gene regulation and detection strategies have been used in the past, this work represents a combination of gene regulation and detection in a single material that operates in a highly efficient manner. $\mathrm{MaBiDz}$ is thus a promising first step toward the development of mRNA-directed theranostics and is expected to combine the advantages of gene therapy with personalized medicine.

Supplementary Materials: Additional experimental results, technical details, and calculations are available online at http:/ / www.mdpi.com/2312-7481/5/2/24/s1.

Author Contributions: S.B. performed most of the experiments with RNA sensing in cells and prepared the paper draft, A.Z. prepared magnetic nanoparticles, S.M. supervised the work with nanoparticles, D.M.K. advised on the work with DNAzymes and edited the paper draft, E.K. supervised the project and edited the final paper draft.

Acknowledgments: This work at Clarkson University (E.K.) and at the University of Georgia (S.M.) was supported by the NSF awards CBET-1403208 and DMR-1309469. The work at University of Central Florida (D.M.K.) was supported by NIH awards R15AI10388001A1 and 1R15CA173703-01. The authors thank Craig Woodworth, Guz, Han Deng, and Elham Honarvarfard for technical assistance and scientific discussions.

Conflicts of Interest: The authors declare no conflicts of interest.

\section{References}

1. Cole, A.J.; Yang, V.C.; David, A.E. Cancer theranostics: The rise of targeted magnetic nanoparticles. Trends Biotechnol. 2011, 29, 323-332. [CrossRef]

2. Palekar-Shanbhag, P.; Jog, S.V.; Chogale, M.M.; Gaikwad, S.S. Theranostics for cancer therapy. Curr. Drug Deliv. 2013, 10, 357-362. [CrossRef] [PubMed]

3. Engelmann, U.M.; Roeth, A.A.; Eberbeck, D.; Buhl, E.M.; Neumann, U.P.; Schmitz-Rode, T.; Slabu, I. Combining bulk temperature and nanoheating enables advanced magnetic fluid hyperthermia efficacy on pancreatic tumor cells. Sci. Rep. 2018, 8, 13210. [CrossRef] [PubMed]

4. Avazzadeh, R.; Vasheghani-Farahani, E.; Soleimani, M.; Amanpour, S.; Sadeghi, M. Synthesis and application of magnetite dextran-spermine nanoparticles in breast cancer hyperthermia. Prog. Biomater. 2017, 6, 75-84. [CrossRef]

5. Breaker, R.R.; Joyce, G.F. A DNA enzyme that cleaves RNA. Chem. Biol. 1994, 1, 223-229. [CrossRef]

6. Santoro, S.W.; Joyce, G.F. A general purpose RNA-cleaving DNA enzyme. Proc. Natl. Acad. Sci. USA 1997, 94, 4262-4266. [CrossRef]

7. Silverman, S.K. Catalytic DNA: Scope, applications, and biochemistry of deoxyribozymes. Trends Biochem. Sci. 2016, 41, 595-609. [CrossRef] [PubMed]

8. Stojanovic, M.N.; Stefanovic, D.; Rudchenko, S. Exercises in molecular computing. Acc. Chem. Res. 2014, 47, 1845-1852. [CrossRef] [PubMed]

9. Gerasimova, Y.V.; Kolpashchikov, D.M. Divide and control: Split design of multi-input DNA logic gates. Chem. Commun. 2015, 51, 870-872. [CrossRef] [PubMed]

10. Xiong, X.; Zhou, C.; Wu, C.; Zhu, G.; Chen, Z.; Tan, W. Responsive DNA-based hydrogels and their applications. Macromol. Rapid Commun. 2013, 34, 1271-1283. [CrossRef] [PubMed]

11. McGhee, C.E.; Loh, K.Y.; Lu, Y. DNAzyme sensors for detection of metal ions in the environment and imaging them in living cells. Curr. Opin. Biotechnol. 2017, 45, 191-201. [CrossRef] [PubMed]

12. Gerasimova, Y.V.; Kolpashchikov, D.M. Folding 16S RNA in a signal-producing structure for detection of bacteria. Angew. Chem. Int. Ed. 2013, 52, 10586-10588. [CrossRef] [PubMed]

13. Fokina, A.A.; Meschaninova, M.I.; Durfort, T.; Venyaminova, A.G.; Francois, J.-C. Targeting insulin-like growth factor I with 10-23 DNAzymes: 2'-o-methyl modifications in the catalytic core enhance mRNA cleavage. Biochemistry 2012, 51, 2181-2191. [CrossRef] [PubMed]

14. Yehl, K.; Joshi, J.P.; Greene, B.L.; Dyer, R.B.; Nahta, R.; Salaita, K. Catalytic deoxyribozyme-modified nanoparticles for RNAi-independent gene regulation. ACS Nano 2012, 6, 9150-9157. [CrossRef] 
15. Zhou, W.; Ding, J.; Liu, J. Theranostic DNAzymes. Theranostics 2017, 7, 1010-1025. [CrossRef]

16. Bakshi, S.F.; Guz, N.; Zakharchenko, A.; Deng, H.; Tumanov, A.V.; Woodworth, C.D.; Minko, S.; Kolpashchikov, D.M.; Katz, E. Magnetic field-activated sensing of mRNA in living cells. J. Am. Chem. Soc. 2017, 139, 12117-12120. [CrossRef] [PubMed]

17. Bakshi, S.F.; Guz, N.; Zakharchenko, A.; Deng, H.; Tumanov, A.V.; Woodworth, C.D.; Minko, S.; Kolpashchikov, D.M.; Katz, E. Nanoreactors based on DNAzyme-functionalized magnetic nanoparticles activated by magnetic field. Nanoscale 2018, 10, 1356-1365. [CrossRef]

18. Kolpashchikov, D.M. A binary deoxyribozyme for nucleic acid analysis. ChemBioChem 2007, 8, $2039-2042$. [CrossRef] [PubMed]

19. Mokany, E.; Bone, S.M.; Young, P.E.; Doan, T.B.; Todd, A.V. MNAzymes, a versatile new class of nucleic acid enzymes that can function as biosensors and molecular switches. J. Am. Chem. Soc. 2010, 132, 1051-1059. [CrossRef]

20. Smith, A.; Kolpashchikov, D.M. Divide and control: Comparison of split and switch hybridization sensor. Chem. Select. 2017, 2, 5427-5431. [CrossRef] [PubMed]

21. Kamar, O.; Sun, S.-C.; Lin, C.-H.; Chung, W.-Y.; Lee, M.-S.; Liao, Y.-C.; Kolpashchikov, D.M.; Chuang, M.-C. A mutation-resistant deoxyribozyme OR gate for highly selective detection of viral nucleic acids. Chem. Commun. 2017, 53, 10592-10595. [CrossRef] [PubMed]

22. Bengtson, H.N.; Homolka, S.; Niemann, S.; Reis, A.J.; da Silva, P.E.A.; Gerasimova, Y.V.; Kolpashchikov, D.M.; Rohde, K.H. Multiplex detection of extensively drug resistant tuberculosis using binary deoxyribozyme sensors. Biosens. Bioelectron. 2017, 94, 176-183. [CrossRef] [PubMed]

23. Zagorovsky, K.; Chan, W.C.W. A plasmonic DNAzyme strategy for point-of-care genetic detection of infectious pathogens. Angew. Chem. Int. Ed. 2013, 52, 3168-3171. [CrossRef] [PubMed]

24. Halo, T.L.; McMahon, K.M.; Angeloni, N.L.; Xu, Y.; Wang, W.; Chinen, A.B.; Malin, D.; Strekalova, E.; Cryns, V.L.; Cheng, C.; et al. NanoFlares for the detection, isolation, and culture of live tumor cells from human blood. Proc. Natl. Acad. Sci. USA 2014, 111, 17104-17109. [CrossRef] [PubMed]

25. Dias, N.; Stein, C.A. Antisense oligonucleotides: Basic concepts and mechanisms. Mol. Cancer Ther. 2002, 1, 347-355. [PubMed]

26. Moreno, P.M.D.; Pêgo, A.P. Therapeutic antisense oligonucleotides against cancer: Hurdling to the clinic. Front. Chem. 2014, 2, 87. [CrossRef] [PubMed]

27. Luo, J. CRISPR/Cas9: From genome engineering to cancer drug discovery. Trends Cancer 2016, 2, 313-324. [CrossRef]

28. Das, S.K.; Menezes, M.E.; Bhatia, S.; Wang, X.Y.; Emdad, L.; Sarkar, D.; Fisher, P.B. Gene therapies for cancer: Strategies, challenges and successes. J. Cell. Physiol. 2015, 230, 259-271. [CrossRef]

29. Prigodich, A.E.; Seferos, D.S.; Massich, M.D.; Giljohann, D.A.; Lane, B.C.; Mirkin, C.A. Nano-flares for mRNA regulation and detection. ACS Nano 2009, 3, 2147-2152. [CrossRef]

30. Plank, C.; Schillinger, U.; Scherer, F.; Bergemann, C.; Rémy, J.-S.; Krötz, F.; Anton, M.; Lausier, J.; Rosenecker, J. The magnetofection method: Using magnetic force to enhance gene delivery. Biol. Chem. 2003, 384, 737-747. [CrossRef]

31. Plank, C.; Zelphati, O.; Mykhaylyk, O. Magnetically enhanced nucleic acid delivery. Ten years of magnetofection-progress and prospects. Adv. Drug Deliv. Rev. 2011, 63, 1300-1331. [CrossRef] [PubMed]

32. Cheng, G.Z.; Chan, J.; Wang, Q.; Zhang, W.; Sun, C.D.; Wang, L.-H. Twist transcriptionally up-regulates AKT2 in breast cancer cells leading to increased migration, invasion, and resistance to paclitaxel. Cancer Res. 2007, 67, 1979-1987. [CrossRef] [PubMed]

(C) 2019 by the authors. Licensee MDPI, Basel, Switzerland. This article is an open access article distributed under the terms and conditions of the Creative Commons Attribution (CC BY) license (http:/ / creativecommons.org/licenses/by/4.0/). 